\title{
Sustainability in Health care by Allocating Resources Effectively (SHARE) 5: developing a model for evidence-driven resource allocation in a local healthcare setting
}

Claire Harris ${ }^{1,2^{*}} \mathbb{D}$, Kelly Allen ${ }^{1,2}$, Cara Waller ${ }^{2}$, Sally Green ${ }^{1}$, Richard King ${ }^{3}$, Wayne Ramsey ${ }^{4}$, Cate Kelly ${ }^{5}$ and Malar Thiagarajan ${ }^{6}$

\begin{abstract}
Background: This is the fifth in a series of papers reporting Sustainability in Health care by Allocating Resources Effectively (SHARE) in a local healthcare setting. This paper synthesises the findings from Phase One of the SHARE Program and presents a model to be implemented and evaluated in Phase Two. Monash Health, a large healthcare network in Melbourne Australia, sought to establish an organisation-wide systematic evidence-based program for disinvestment. In the absence of guidance from the literature, the Centre for Clinical Effectiveness, an in-house 'Evidence Based Practice Support Unit', was asked to explore concepts and practices related to disinvestment, consider the implications for a local health service and identify potential settings and methods for decision-making.

Methods: Mixed methods were used to capture the relevant information. These included literature reviews; online questionnaire, interviews and structured workshops with a range of stakeholders; and consultation with experts in disinvestment, health economics and health program evaluation. Using the principles of evidence-based change, the project team worked with health service staff, consumers and external experts to synthesise the findings from published literature and local research and develop proposals, frameworks and plans.

Results: Multiple influencing factors were extracted from these findings. The implications were both positive and negative and addressed aspects of the internal and external environments, human factors, empirical decisionmaking, and practical applications. These factors were considered in establishment of the new program; decisions reached through consultation with stakeholders were used to define four program components, their aims and objectives, relationships between components, principles that underpin the program, implementation and evaluation plans, and preconditions for success and sustainability. The components were Systems and processes, Disinvestment projects, Support services, and Program evaluation and research. A model for a systematic approach to evidence-based resource allocation in a local health service was developed.
\end{abstract}

Conclusion: A robust evidence-based investigation of the research literature and local knowledge with a range of stakeholders resulted in rich information with strong consistent messages. At the completion of Phase One, synthesis of the findings enabled development of frameworks and plans and all preconditions for exploration of the four main aims in Phase Two were met.

Keywords: Health technology, TCP, Disinvestment, Decommission, De-adopt, Resource allocation, Decision-making, Implementation, Model, Framework

\footnotetext{
* Correspondence: claire.harris@monash.edu

${ }^{1}$ School of Public Health and Preventive Medicine, Monash University,

Victoria, Australia

${ }^{2}$ Centre for Clinical Effectiveness, Monash Health, Victoria, Australia

Full list of author information is available at the end of the article
} 


\section{About SHARE}

This is the fifth in a series of papers reporting Sustainability in Health care by Allocating Resources Effectively (SHARE). The SHARE Program is an investigation of concepts, opportunities, methods and implications for evidence-based investment and disinvestment in health technologies and clinical practices in a local healthcare setting. The papers in this series are targeted at clinicians, managers, policy makers, health service researchers and implementation scientists working in this context. This paper synthesises the findings from Phase One of the SHARE Program and presents a model to be implemented and evaluated in Phase Two.

\section{Background}

Health technologies and clinical practices (TCPs) are defined as therapeutic interventions (including prostheses, implantable devices, vaccines, pharmaceuticals and medical, surgical or other clinical procedures) and diagnostic procedures [1]. Most new TCPs are assessed for safety, effectiveness and cost-effectiveness before they become widespread practice. However there are many longstanding practices that were introduced before rigorous evaluation was required and some recently developed TCPs have been implemented prematurely due to early promise of large benefits, vigorous marketing and patients' and professionals' desire for 'state of the art' care [2]. As new research emerges it has become clear that some TCPs in current practice do not meet contemporary standards of evidence based care, have been superseded or have become obsolete.

Cessation of TCPs that are potentially harmful, shown to be ineffective, or where a more effective or costeffective alternative is available has the dual advantage of improving patient care and allowing for a more efficient use of available resources. This concept has become known as 'disinvestment'. While a lack of common terminology in this area has been noted [3-8], and the multiple definitions for disinvestment are based on different principles [9], the broad concept of removing, reducing or restricting practices that do not work or could be done better or more cheaply is welcome, potentially increasing health benefits without increasing spending.

After implementing a rigorous evidence-based program for assessment of new TCPs prior to their introduction [1], senior leaders at Monash Health (previously Southern Health), a large health service network in Melbourne, Australia, sought to investigate possibilities for a program of disinvestment through the 'Sustainability in Health care by Allocating Resources Effectively' (SHARE) Program. The SHARE Program was undertaken by the Centre for Clinical Effectiveness (CCE), an in-house resource to facilitate Evidence Based Practice. An overview of the SHARE Program, a guide to the SHARE publications and further details about Monash Health and CCE are provided in the first paper in this series [2].

The preliminary proposal was for a systematic approach that would integrate systems and processes for transparent, accountable and evidence-based decision-making across the health service. However there is little evidence to inform development of organisation-wide systematic approaches to disinvestment at the local level [7, 10-16].

In the absence of guidance from the literature, a twophased process was proposed to identify and then evaluate potential opportunities for disinvestment at Monash Health (Fig. 1). The aim of Phase One was to understand concepts and practices related to disinvestment and the implications for a local health service and, based on this information, to identify potential settings and methods for decision-making. The aim of Phase Two was to implement and evaluate the proposed methods to determine which were sustainable, effective and appropriate at Monash Health.

\section{Aims}

The aim of this project was to develop a proposal for an organisation-wide, systematic, integrated, transparent, evidence-based approach to disinvestment.

The aims of this paper are to outline how the information was collected, synthesised and developed into a proposal for change and to introduce a model of the program to enable replication and testing.

\section{Research questions}

What are the implications for disinvestment at Monash Health?

What is the most appropriate and effective approach to organisation-wide, systematic, integrated, evidencedriven disinvestment at Monash Health?

Can a model for evidence-driven resource allocation in the local healthcare setting be derived from the Monash Health program to enable replication and testing?

\section{Methods \\ Design \\ Model for evidence-based change}

The SHARE Program was undertaken using the SEAchange model for Sustainable, Effective and Appropriate evidence-based change in health services [17]. The model involves four steps: identifying the need for change, developing a proposal to meet the need, implementing the proposal and evaluating the extent and impact of the change. Each step is underpinned by the principles of evidence-based practice to ensure that the best available evidence from research and local data, the experience and expertise of health service staff and the values and perspectives of consumers are taken into account. Sustainability, avoidance of duplication and 


\begin{tabular}{|c|c|c|}
\hline \multicolumn{3}{|c|}{$\begin{array}{l}\text { SHARE } \\
\text { Sustainability in Health care by Allocating Resources Effectively }\end{array}$} \\
\hline \multicolumn{2}{|c|}{ PHASE ONE } & PHASE TWO \\
\hline $\begin{array}{c}\text { STEP 1 } \\
\text { Identify need for change } \\
\end{array}$ & $\begin{array}{c}\text { STEP 2 } \\
\text { Develop proposal for change } \\
\end{array}$ & $\begin{array}{c}\text { STEP } 4 \\
\text { Evaluate outcomes of change }\end{array}$ \\
\hline $\begin{array}{l}\text { - What concepts, definitions and } \\
\text { perspectives underpin } \\
\text { disinvestment? } \\
\text { - What models or methods of } \\
\text { disinvestment have been } \\
\text { implemented in hospitals or } \\
\text { health services? } \\
\text { - Where are the opportunities } \\
\text { for systematic decisions about } \\
\text { disinvestment in a local health } \\
\text { service? } \\
\text { - Where, how and by whom are } \\
\text { decisions about resource } \\
\text { allocation made, implemented } \\
\text { and evaluated at Monash } \\
\text { Health? What factors influence } \\
\text { these processes? } \\
\text { - What knowledge or experience } \\
\text { of disinvestment exists within } \\
\text { Monash Health? } \\
\text { - How can consumer values and } \\
\text { preferences be integrated into } \\
\text { organisation-wide decision- } \\
\text { making? }\end{array}$ & $\begin{array}{l}\text { - What are the implications for } \\
\text { disinvestment at Monash } \\
\text { Health? } \\
\text { - What is the most appropriate } \\
\text { and effective approach to } \\
\text { enable organisation-wide, } \\
\text { systematic, integrated, } \\
\text { evidence-driven decision- } \\
\text { making for disinvestment at } \\
\text { Monash Health? } \\
\text { - Can a model for evidence- } \\
\text { driven resource allocation in } \\
\text { the local healthcare setting be } \\
\text { derived from the Monash } \\
\text { Health program to enable } \\
\text { replication and testing? }\end{array}$ & $\begin{array}{l}\text { Aim 1. Systems and Processes } \\
\text { To develop, implement and evaluate systems and processes for } \\
\text { organisation-wide systematic, transparent, accountable and } \\
\text { evidence-based decision-making } \\
\text { Aim 2. Disinvestment Projects } \\
\text { To develop, implement and evaluate methods to } \\
\text { - identify and prioritise potential disinvestment opportunities } \\
\text { - undertake evidence-based disinvestment projects } \\
\text { Aim 3. Support Services } \\
\text { To develop, implement and evaluate methods to } \\
\text { - deliver evidence from research and data to decision-makers } \\
\text { - build capacity in evidence-based decision-making and } \\
\text { implementation and evaluation of evidence-based decisions } \\
\text { - support staff in project conduct and administration } \\
\text { Aim } 4 \text {. Program Evaluation, Research and Dissemination } \\
\text { - To undertake evaluation to measure outcomes } \\
\text { - To undertake action research to understand processes } \\
\text { - To deliver a national workshop to share knowledge and } \\
\text { experience of disinvestment and develop links for collaboration } \\
\text { - To disseminate learning through publications and presentations }\end{array}$ \\
\hline \multicolumn{3}{|c|}{$\begin{array}{l}\text { Take an evidence-based approach: each step underpinned by Evidence from research and local data, Experience and expertise of health } \\
\text { service staff, and Values and perspectives of consumers } \\
\text { Address systems issues: Ensure sustainability through structure, skills, resources, leadership and commitment; Avoid duplication; and } \\
\text { Integrate with existing systems } \\
\text { Use action research methods: Document, investigate and learn from barriers and enablers encountered in the change process }\end{array}$} \\
\hline
\end{tabular}

integration of new processes within existing systems are also considered at each step. An action research component enables continuous investigation of the change process to improve the current project and inform future work. The research questions for this paper relate to development of a proposal for change (Fig. 1).

\section{Framework for design and evaluation of complex interventions}

The two-phased approach taken in SHARE is consistent with the UK Medical Research Council framework for design and evaluation of complex interventions [18]. Phase One involved specifying the context, understanding the problem and defining the components of an optimal intervention. Phase Two was an exploratory trial assessing acceptability and feasibility of the components and identifying methodological issues for implementation and evaluation. These two phases are mapped to the four steps in the model for evidence-based change (Fig. 1).

\section{Data collection methods and sources}

Literature reviews, surveys, interviews and workshops were used to capture the relevant information in Step 1 (Fig. 1). An overview is provided in Table 1 and full details of methods and sources are reported in Additional file 1.

\section{Development of proposal for change Project team reflection}

An action research approach was adopted based on the 'researcher as facilitator for change' model defined by Meyer; researchers working explicitly with and for people rather than undertaking research on them [19, 


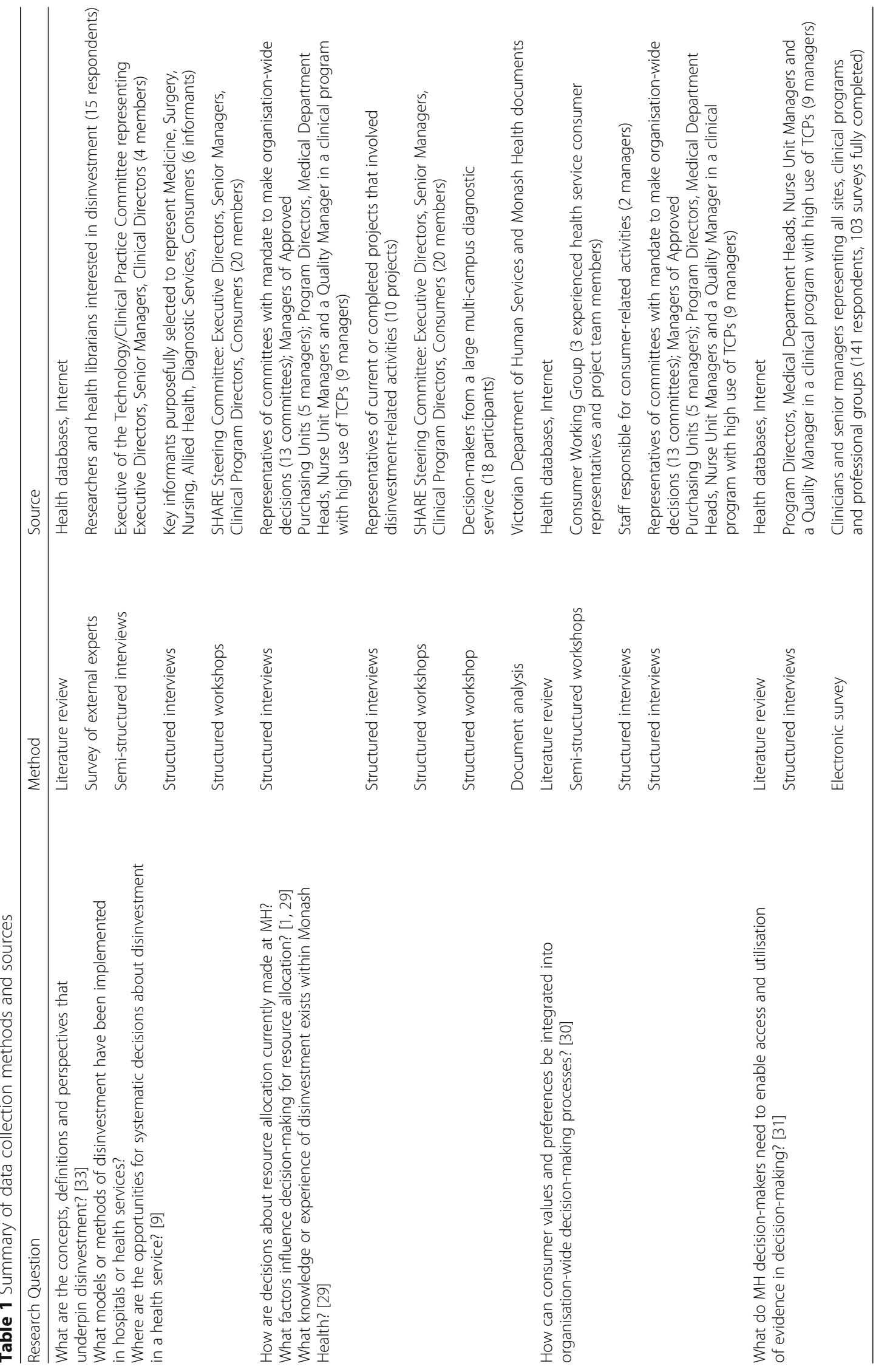


20]. In this capacity, CCE staff were both the SHARE project team and the action researchers.

CCE staff had regular and ongoing contact over many years with clinicians and managers involved in projects across Monash Health and were familiar with organisational practices, expertise of project staff, available resources, project methods and outcomes. As the SHARE project team, they were able to contribute this knowledge in discussions and decision-making settings.

Observations and reflections of the project team were used for ongoing improvements to the program components and implementation process. An agenda item for 'Learning' was scheduled at the beginning of every team meeting. Participants were invited to consider anything that had affected the project since the last meeting using the framework 'what worked, what didn't, why and how it could be improved'. Each issue, its effect on the project and potential changes that would build on positive outcomes or remove or minimise future problems were discussed. The learning and actions were documented; actions were assigned, given timeframes and followed up to ensure completion.

\section{Analysis and synthesis}

Outcomes of consultations and findings from initial interviews with small numbers of participants were simply documented and collated using MS Word or Excel. Workshop and subsequent interview findings were collated in MS Word, Excel and/or Nvivo [21] and analysed thematically by either content analysis [22] to identify emergent themes, or framework analysis [23] when categories had been specified a priori. Details of individual project protocols are provided in Additional file 1.

Using the principles of evidence-based change [17], the project team worked with health service staff, consumers and external experts to collate and summarise the findings from published literature and local research and identify the implications for a disinvestment program at Monash Health from the emergent themes.

\section{Drafting, review and authorisation of components and activities}

Emergent themes were developed into components of the proposed program. Draft proposals, frameworks and plans were developed, reviewed and refined with input from local stakeholders and relevant experts via workshops, presentations and discussions with individuals and groups, consultations and informal discussions (Table 2). Details of structured workshops are provided in Additional file 1, Table E. Decisions were made by the SHARE Steering Committee in workshops held at scheduled committee meetings. Discussion papers and background documents were provided beforehand, formal presentations introduced the workshops, and topics for discussion and decisions required were listed on the agenda. Discussion was informal within the structure of the agenda and decisions were based on consensus. The program was endorsed by the Executive Management Team and Monash Health Board.

\section{Assessment of sustainability}

A checklist of factors for success and sustainability, adapted from the work of others [24-27] for use in CCE projects, was used to assess whether there was adequate provision of relevant requirements (structure, skills, resources, commitment and leadership) to achieve and maintain the program components and activities (Table 3) [17].

\section{Development of a model}

Frameworks and models are derived from a set of concepts and the relationships between the concepts to facilitate the development of propositions. The components of the proposed SHARE Program were used as the concepts within the model. Relationships and propositions were derived from the identified needs and a set of sequential processes that emerged from the literature and local findings.

The robustness and usefulness of the proposed model were analysed using the domains outlined for this purpose by Rycroft-Malone and Bucknall [28].

\section{Results}

Results of the literature searches and the response rates and representativeness of participants in surveys, interviews and workshops are included in Additional file 1, Tables A-E. Complete surveys were received from 15 external experts and 118 local respondents, and 90 individuals participated in interviews and workshops. Many participated more than once: as either a representative of more than one role, for example as a committee chair interviewed on one topic and as a clinical department head responding to a survey on another, or to address more than one question, such as a member of the Steering Committee participating in several decision-making workshops.

Data collected from these activities informed a range of research questions. Findings related to research questions not addressed in this paper are reported in other SHARE publications [9, 29-33].

\section{What are the implications for disinvestment at Monash Health?}

Multiple factors for consideration in establishment of the new program were identified. Messages from the literature were consistent with the views of experts and local stakeholders. The findings, sources they were ascertained from, decisions resulting from consultation with stakeholders, and relevant program elements are presented in Table 4. 
Table 2 Summary of program development

\begin{tabular}{|c|c|c|}
\hline Objective & Method & Stakeholders and/or Experts \\
\hline $\begin{array}{l}\text { To explore, develop and authorise all } \\
\text { program elements, documents and proposals }\end{array}$ & $\begin{array}{l}\text { Structured workshops on specific issues and } \\
\text { general discussions at routine meetings }\end{array}$ & $\begin{array}{l}\text { SHARE Steering Committee: Executive Directors, } \\
\text { Clinical Program Directors, Senior Managers } \\
\text { and Consumers. }\end{array}$ \\
\hline $\begin{array}{l}\text { To discuss findings of literature review and } \\
\text { Consumer Working Group, refine draft consumer } \\
\text { participation framework and identify additional issues }\end{array}$ & Structured workshop & Monash Health Community Advisory Committee \\
\hline To incorporate feedback from Monash Health leaders & $\begin{array}{l}\text { Presentations and discussions with } \\
\text { individuals and groups }\end{array}$ & $\begin{array}{l}\text { Individuals: All Medical Program Directors and } \\
\text { General Manager of Allied Health; Groups: } \\
\text { Nursing Executive }\end{array}$ \\
\hline To incorporate feedback from Monash Health staff & Invitation to provide contribution & $\begin{array}{l}\text { All staff via the 'All Staff' email list; and staff } \\
\text { interacting with the project team }\end{array}$ \\
\hline To incorporate high level expertise & Consultation & Health Program Evaluator and Health Economist \\
\hline $\begin{array}{l}\text { To determine communication issues and } \\
\text { requirements }\end{array}$ & Consultation & $\begin{array}{l}\text { Monash Health Public Affairs and Communication } \\
\text { Department }\end{array}$ \\
\hline $\begin{array}{l}\text { To enhance compatibility and alignment with state } \\
\text { health department objectives and funding strategies }\end{array}$ & Consultation & $\begin{array}{l}\text { Victorian Department of Human Services Health } \\
\text { Technology Unit }\end{array}$ \\
\hline $\begin{array}{l}\text { To seek endorsement and support at the } \\
\text { highest levels }\end{array}$ & Presentations and discussions with groups & $\begin{array}{l}\text { Executive Management Team; and Monash } \\
\text { Health Board }\end{array}$ \\
\hline
\end{tabular}

The influencing factors were both positive and negative and addressed aspects of the internal and external environments, human factors, empirical decision-making, and practical applications.

Many of the fundamental decisions in development of the program, such as what to call it and what approach to take, were influenced by both positive and negative factors. For example, respondents felt that the program needed a name that engendered support rather than suspicion and a strong positive image that focused on 'effective application of health resources', which was seen as constructive, rather than on disinvestment which was viewed cynically as a strategy to 'save money'. These findings underpinned the decision to change the name from the 'Disinvestment Project' to the 'Sustainability in Health care by Allocating Resources Effectively' Program. 'SHARE' evoked positive emotions and was compatible with iCARE, a term familiar to all staff as the acronym for the Monash Health values (Integrity, Compassion, Accountability, Respect and Excellence). On a less positive note, respondents perceived significant limitations in organisational decision-making and anticipated that if there was a lack of transparency and accountability in the process of reallocation of resources from disinvestment activities it would be a significant barrier to effective implementation of the program. Based on these findings, transparency and accountability became key principles of the program and all the new systems, processes and decision-making criteria would be made explicit.

Many of the human factors identified are common in health service change initiatives. Although there were a few exceptions, Monash Health staff did not routinely seek evidence for decisions, were generally unaware of best practice in implementation and did not usually evaluate outcomes of decisions. The main barriers to use of evidence and effective implementation and evaluation were lack of time, knowledge, skills and resources. These factors led to proposals for support services to assist staff in making, implementing and evaluating evidencebased decisions.

The lack of information on how to establish organisation-wide systems and processes for disinvestment meant that Monash Health had to rely on empirical reasoning for some decisions. As a result of this approach, two features of the SHARE Program differ significantly from the types of disinvestment activities reported in the literature at the time. Firstly, it was thought that disinvestment should be considered alongside investment in the context of all resource allocation decisions, in contrast to many published examples where it was viewed in isolation. Secondly, a systematic, integrated approach was thought to be better than individual projects that may be driven by ad hoc decisions or individuals 'championing' causes. These concepts are reflected in the principles underpinning the SHARE Program.

A number of practical issues were identified across the range of potential activities. Many of these related to factors for success and sustainability of the program such as endorsement, support and strategic direction from the highest level, links to those with power and influence in the organisation, funding, expertise and stakeholder engagement.

What is the most appropriate and effective approach to organisation-wide, systematic, integrated, evidencedriven disinvestment at Monash Health?

Characteristics of the most appropriate and effective approach for Monash Health were identified from the 
Table 3 Factors for success and sustainability

Success: A proposal is more likely to be successfully implemented if it meets the following criteria.

- It is based on sound evidence or expert consensus

- It is presented by a credible organisation

- It can be tested and adapted

- The relative advantage is evident

- It is of low complexity

- It is compatible with the status quo

- It has an attractive and accessible format

Sustainability: A proposal is more likely to be sustainable if it has appropriate and adequate provision in each of the following categories.

- Structure

- Skills

- Resources

- Commitment

- Leadership

published literature and local research. These findings underpinned the decisions that defined the program elements (Table 4). These include program components, their aims and objectives, principles that underpin the program, implementation and evaluation plans, and preconditions for success and sustainability.

\section{Program components, aims and objectives}

Systems and processes Aim 1: To develop, implement and evaluate organisation-wide systematic, transparent, accountable and evidence-based decision-making systems and processes for resource allocation related to health technologies and clinical practices.

The original aim of the team driving the SHARE initiative was to consider disinvestment in a systematic way, integrating systems and processes for decisionmaking across the organisation. This was confirmed as the best approach and the earlier aim was refined to replace 'disinvestment' with 'resource allocation'. The proposed objectives involved investigation of six potential settings for decision-making (Fig. 2). Firstly, the nature of the innovations and methods to deliver them would be explored, those thought to be feasible would then be piloted and those found to be sustainable, effective and appropriate would finally be established as ongoing processes.

Disinvestment projects Aim 2: To identify target disinvestment opportunities, establish prioritisation and decision-making processes and develop, implement and evaluate evidence-based disinvestment projects.

It was anticipated that in the longer term the new systems and processes would identify opportunities for disinvestment activities, however the Steering Committee wanted to explore disinvestment projects immediately. This meant that methods to identify and prioritise target TCPs and then implement and evaluate projects to disinvest them must be investigated in parallel to the new organisational systems and processes. These innovations and methods would be explored, piloted and implemented using the approach outlined in Aim 1.

Support services Aim 3: To develop, implement and evaluate support services to provide expertise and facilitate action.

It was clear from the preliminary work that, in order to achieve the first two aims, services to support the proposed activities and build staff capacity and capability would be required. Key areas of need were identified: providing expertise to deliver research evidence and local data to decision-makers, training and supporting staff to use evidence in decision-making and then implement and evaluate their decisions, and training and supporting staff in project methods and administration.

Program evaluation and research Aim 4: To undertake evaluation and research to assess outcomes, understand the process of change and disseminate the findings.

Although each of the first three components included evaluation in the pilot and implementation phases, it was decided to specify a fourth component to highlight the importance of evaluation, research and dissemination in capturing and understanding what happened and sharing this with others interested in developing similar models. Standard health program evaluation methods would be used to assess outcomes, and action research methods would be included to learn about the processes, what worked, what didn't and why. Running a national workshop was proposed so that the Monash Health team could learn from others with experience in related activities, contribute what had been learned at this point in the SHARE Program, and publish the findings to address some of the gaps in the current literature [34, 35].

\section{Principles}

A series of principles to underpin the program were identified. These captured the focus of the program (effective application of health resources and decisionmaking across the continuum from investment to disinvestment), the general approach to program initiatives (evidence-driven decisions and evidence-based development, implementation and evaluation of projects), and specific strategies (routine, reactive and proactive decision-making processes; top-down and bottom-up activities; and alignment with organisational goals and business plans).

\section{Preconditions}

A number of preconditions were identified to enable this complex multifaceted program to be achieved and maintained. Strategic direction, influence, support and 


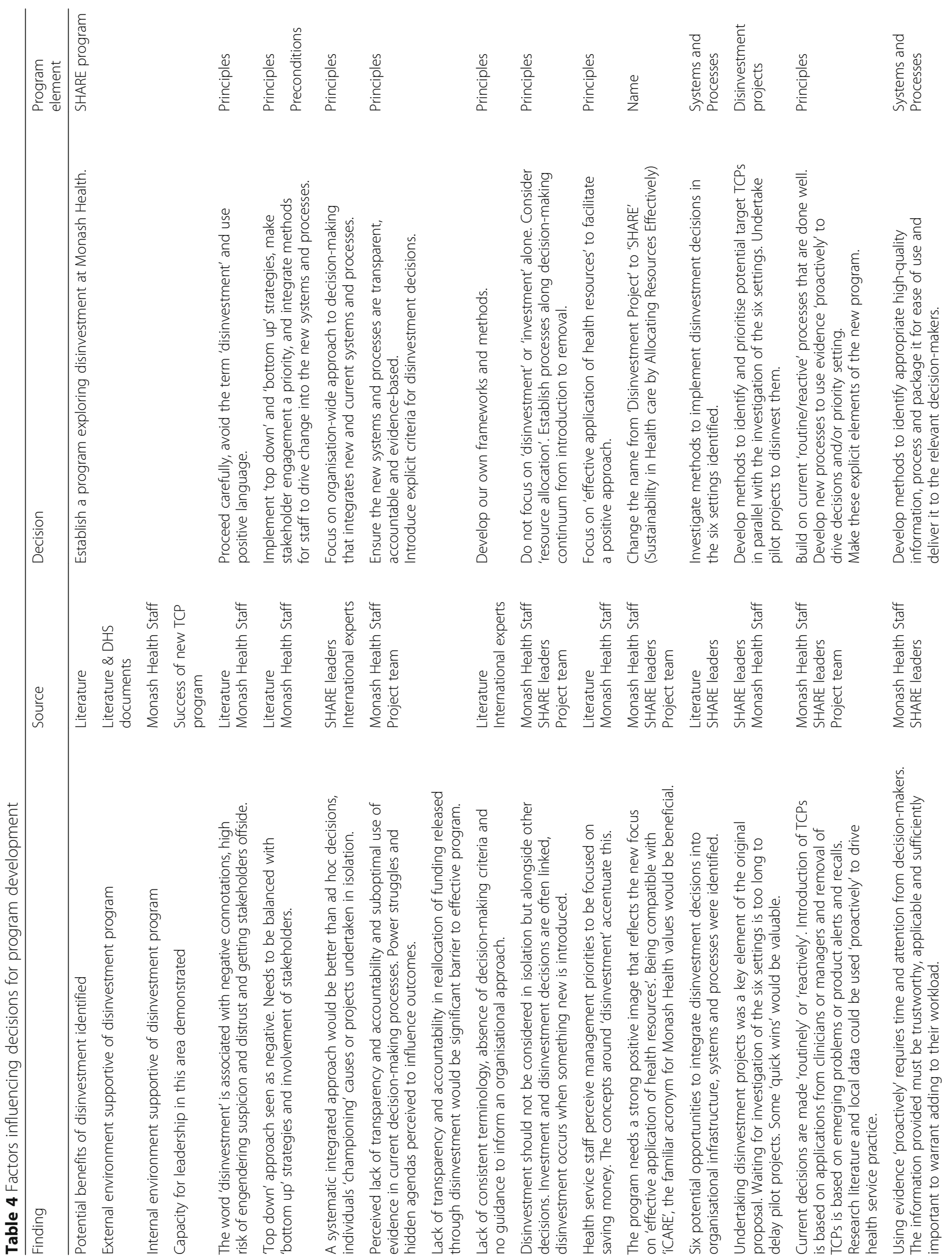




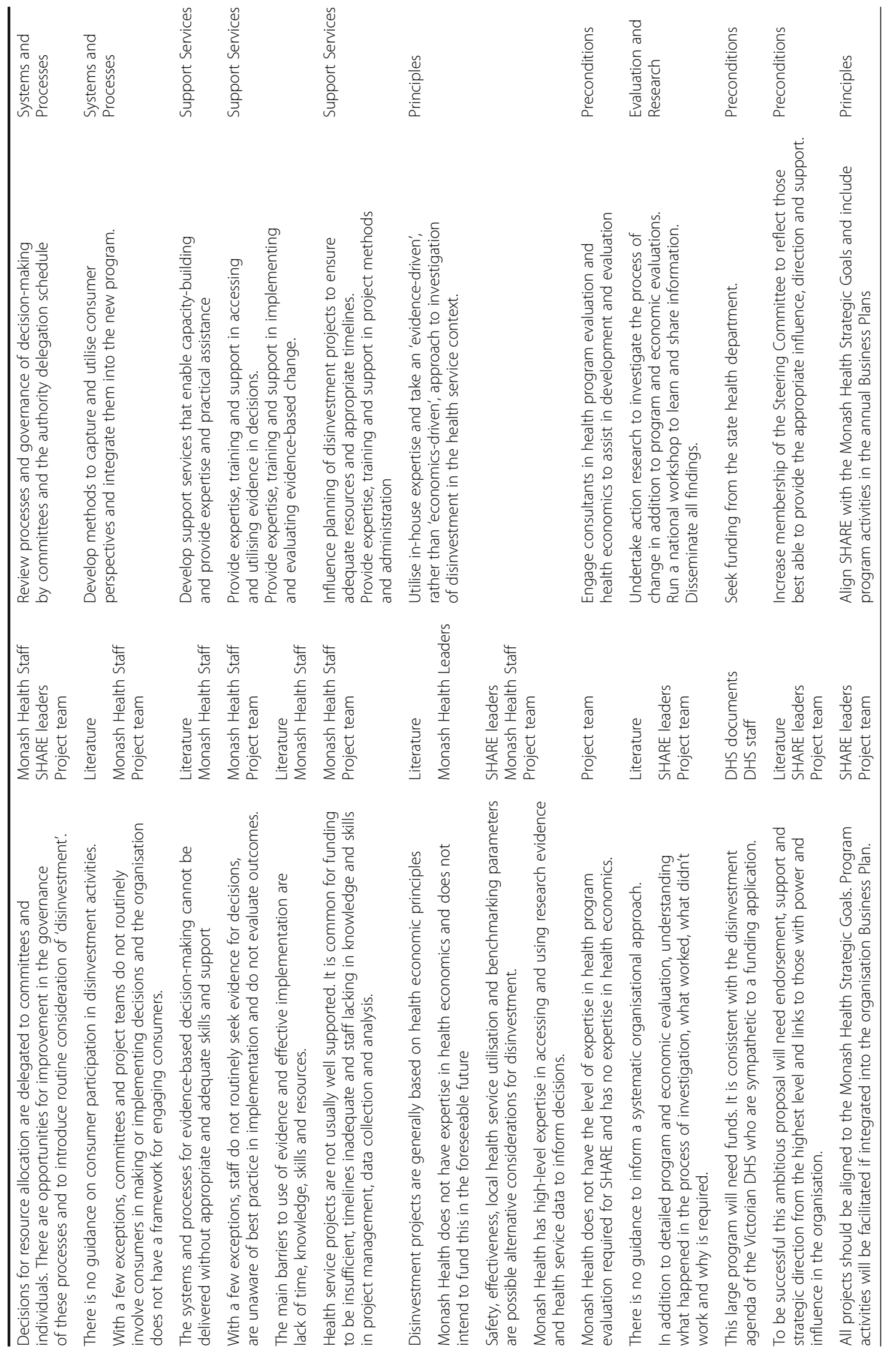




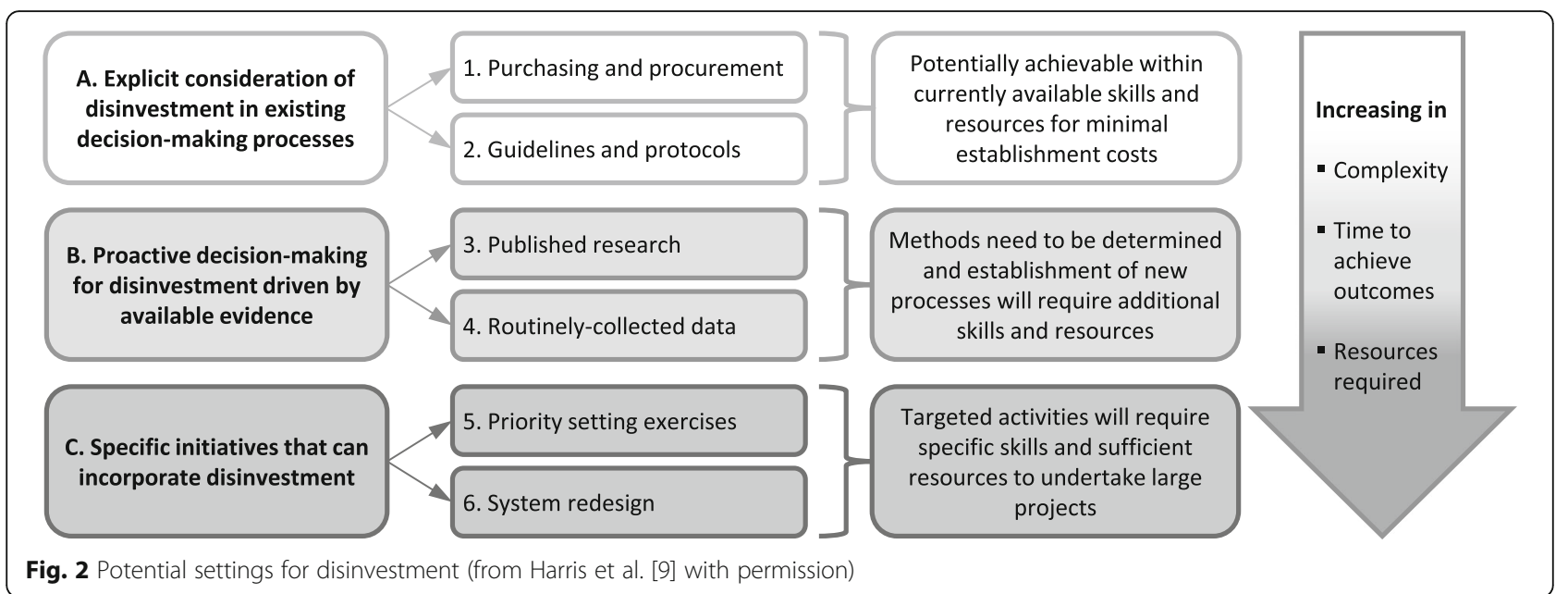

endorsement would be provided by expanding the Steering Committee. Adequate funding was allocated by Monash Health and the Victorian Department of $\mathrm{Hu}$ man Services (DHS). Expertise was sourced in-house and gaps were filled through engagement of expert consultants in health program evaluation and health economics. Organisational readiness for change had been demonstrated and ongoing stakeholder engagement was specified as a priority.

\section{Assessment of sustainability}

A formal review using the checklist for sustainability developed by CCE was undertaken to assess factors related to structure, skills, resources, commitment and leadership (Table 5). A proposal is more likely to be sustainable if it has appropriate and adequate provision in each category. The SHARE Program met all the requirements adequately.

\section{Implementation}

The SHARE Program emerged as a series of projects within each of the four components. Individual implementation plans were developed for each project with strategies based on assessment of barriers and enablers in the relevant context. The interventions were piloted and refined prior to final implementation. These details are published separately [29-32, 36, 37].

The overall program had a general implementation plan couched in terms of timelines and deliverables [38]. Broad consideration of barriers and enablers at the program level was undertaken in the analysis of 'implications for disinvestment at Monash Health' and these were addressed in development of the 'most appropriate model'.

\section{Evaluation}

A formal Evaluation Framework and Plan was created and included evaluation domains, audience, scope, evaluation questions, sources of data, methods of collection and analysis, reporting and timelines [38]. This was considered to be a dynamic document that could be revised during the program.

An external health program evaluator consulted to the SHARE Program in the role of 'critical friend' [38] and a health economist provided expertise and advice for economic evaluations.

A theoretical framework for evaluation of implementation of an evidence-based innovation was used [2] and an outcomes hierarchy based on the SHARE Program components was developed and included in the Evaluation Framework [38].

Due to the size and complexity of SHARE, and its interconnectedness with other Monash Health activities, advice from the SHARE health economist was that an economic evaluation of the overall program would not be possible. Economic evaluation would be limited to the disinvestment pilot projects.

Each of the individual projects in the second phase of SHARE had their own evaluation plans which are reported separately $[31,32,36]$.

\section{Can a model for evidence-driven resource allocation in the local healthcare setting be derived from the SHARE Program to enable replication and testing? Framework}

The purpose of a framework is to provide a frame of reference, organise and focus thinking and assist interpretation. Frameworks are descriptive, tend to be high-level and can apply to a wide variety of situations $[28,39]$.

A framework for SHARE was developed and revised. It was used to clarify thinking; inform purpose, direction and planning; and act as a communication tool.

The initial draft was created to facilitate discussion by the project team and Steering Committee to establish the nature and direction of the program (Table 6). It introduced three main concepts. 
Table 5 Assessment of sustainability

\section{Structure}

- A Steering Committee is in place with appropriate Terms of Reference and members that can deliver the required strategic direction, influence and support

- A Project Team is in place with clear timelines and deliverables

- Areas of responsibility are defined and lines of reporting and accountability are clear

Skills

- The Steering Committee has expertise in clinical practice, management, finances, operations, legal, ethics, research, information technology, procurement and biomedical engineering

- The Project Team has expertise in evidence based practice, knowledge brokerage, implementation and evaluation of change

- Additional expertise is available

- Collection and analysis of health service utilisation and cost data (Monash Health Clinical Information Management unit)

- Program evaluation and health economics (Consultants)

Resources

- Appropriate funding has been obtained from Monash Health and Victorian Department of Human Services

- Accommodation and infrastructure for project team provided within the Centre for Clinical Effectiveness

Commitment

- Monash Health has committed significant funding and program activities are included in the Business Plan

- The Board and Executive Management Team have endorsed the program

- Three Executive Directors are on the Steering Committee

- The Centre for Clinical Effectiveness has prioritised development of organisational infrastructure to support evidence-based practice as a key element in its workplan

Leadership

- The same team that developed the award-winning new technology program are leading the SHARE program

- Monash Health has expressed a wish to be leaders in disinvestment

- The Victorian Department of Human Services has expressed a wish to be leaders in disinvestment

- The Centre for Clinical Effectiveness is a leader in enabling evidencebased decision-making

- The Steering Committee carries influence (Executive Directors, Program Directors, Senior Management)

- The original plan for a project about 'disinvestment' was reframed to a program addressing the spectrum of decisions from investment to disinvestment across the organisation.

- There are existing processes at Monash Health for introduction of new TCPs and removal of TCPs in current use, but these are usually 'reactive' decisions made in response to internal applications or external notifications.
- Evidence from published research and local data could be used 'proactively' to drive decision-making.

A revised draft was developed to reflect subsequent decisions and was used for presentations to the Executive Management Team and the Board to seek endorsement and to the Victorian DHS for funding (Fig. 3). It retained the key concepts noted above and introduced another two.

-The six settings identified as potential opportunities for decision-making in a systematic, integrated organisation-wide program should be explored across the continuum from investment to disinvestment and should address routine, reactive and proactive decisionmaking processes.

- A 'program' of integrated systems and processes identifying TCPs for introduction, restriction or removal would initiate and direct a series of methodologically rigorous 'projects' implementing the desired changes.

\section{Model}

A model is more precise and more prescriptive than a framework. It is narrower in scope, the concepts are well defined and the relationships between them are specific. Models are representations of the real thing $[28,39]$.

The final representation of the SHARE Program, created for this paper, captures all the program elements and their relationships (Fig. 4). It is precise, prescriptive and provides sufficient detail to be a model for a systematic approach to evidence-based resource allocation in a local health service.

Concepts The components of the proposed SHARE Program (aims and objectives, underpinning principles, preconditions for success and sustainability) are the concepts within the model.

Relationships The initial proposal had two aims, to develop systems and processes for decision-making and to undertake disinvestment projects. The systems and processes would lead to identification of target TCPs to be disinvested in individual projects. This sequential process is represented by an arrow from Aim 1 to Aim 2.

Based on information from the literature and stakeholder feedback it was clear that these two aims would

Table 6 Initial draft of SHARE framework

\begin{tabular}{|c|c|}
\hline Introduction of safe, effective, cost-effective TCPs & Removal of harmful, ineffective, inefficient TCPs \\
\hline $\begin{array}{l}\text { Reactive (current) } \\
\text { - Application process }\end{array}$ & $\begin{array}{l}\text { Reactive (current) } \\
\text { - Drug alerts, product withdrawals }\end{array}$ \\
\hline $\begin{array}{l}\text { Proactive (potential) } \\
\text { - Identification of evidence regarding new TCPs that are safer, } \\
\text { more effective or more cost-effective }\end{array}$ & $\begin{array}{l}\text { Proactive (potential) } \\
\text { - Identification of evidence regarding TCPs in current practice that are less } \\
\text { safe, less effective or less cost-effective }\end{array}$ \\
\hline
\end{tabular}




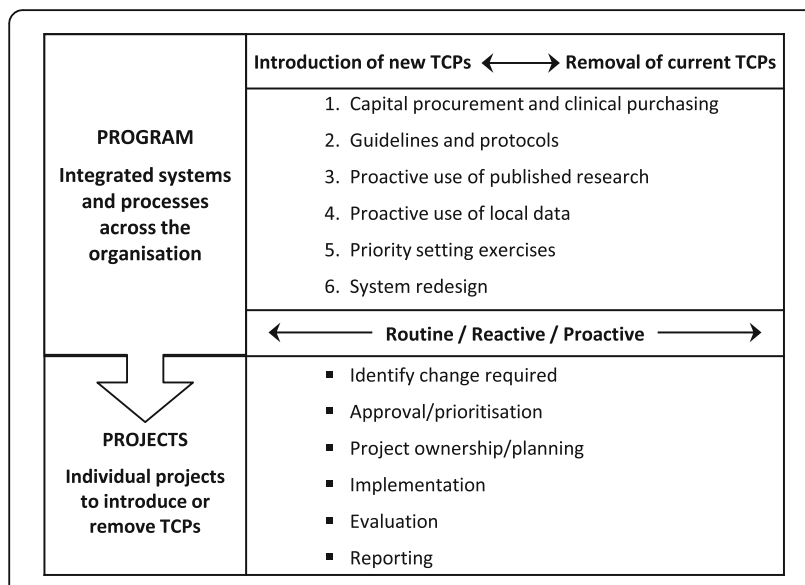

Fig. 3 Revised draft of SHARE framework

not be successful without provision of expertise and support to facilitate decision-making (systems and processes) and implementation of change (projects). These needs are represented by arrows from Aim 3 to Aims 1 and 2 .

Detailed program evaluation and research to measure and understand the change process were considered to be a vital fourth component and would be applied to the other three components. The double headed arrows between Aim 4 and Aims 1, 2 and 3 indicate that evaluation and research inform further development of the components which in turn would be evaluated and researched.

The Principles and Preconditions sit above and below the four aims indicating that they apply to the whole program.

Propositions A series of propositions can be derived from the components and their relationships.

- Systems and processes will be required for systematic, integrated, transparent, accountable, evidence-based decision-making in an organisationwide approach to identification of potential disinvestment opportunities.

- Projects arising from these decisions will be undertaken to confirm potential benefits, harms and the priorities for disinvestment of identified targets, and implement and evaluate disinvestment where appropriate.

- Support services that provide expertise, training and support to decision-makers and project staff in finding and using evidence from research and local data in decision-making, implementation, evaluation and project management will be required for the systems, processes and projects to be successful.

- Evaluation and research of the systems, processes, projects and support services will inform and enable quality improvement, organisational learning and development, and will add to the body of knowledge on disinvestment.

Characteristics of the model The model is primarily descriptive to enable application in a local healthcare service and allow replication and testing. It was developed using both deductive and inductive methods. Although not based on a specific theory, it has potential to facilitate future theory development and/or testing. Specific characteristics of the model and potential for its use, as discussed in the sections above, are summarised in Table 7 using domains and criteria developed to assess the robustness and utility of proposed models and frameworks [28]. This overview enables potential users to identify whether the model will meet their aims and be applicable to their situation.

\section{Discussion \\ Strengths}

The main strengths of this process arise from the evidence-based and explicit approach. Decisions were based on information from the research literature and local data collected for this purpose, integrated with the views of experts in the field and local health service staff and consumers. This approach facilitates development of strategies that are more likely to be sustainable, effective and appropriate $[17,40]$. The broad stakeholder involvement enables local ownership and the transparency of the process leads to trust.

A rigorous evidence-based approach was possible due to the provision of adequate resources. CCE staff had appropriate skills for this work and adequate time was allocated to undertake it.

The timing of the project was opportune as internal and external environments were both amenable to exploration of disinvestment. The international literature on methods of disinvesting individual TCPs was building, the Victorian DHS was exploring the role of disinvestment at state level and all the staff and consumers approached were constructive in their responses. Monash Health had already demonstrated commitment and leadership to evidence-based decision-making with the new Technology/Clinical Practice Program [1]. The preliminary work for SHARE was able to capitalise on this momentum.

Staff and consumers were in agreement in their responses. Themes regarding current practice, proposals for change and barriers and enablers were strong and consistent across all participant groups.

The key messages arising from local responses were consistent with the literature at the time and remain consistent with current publications [41, 42]. 


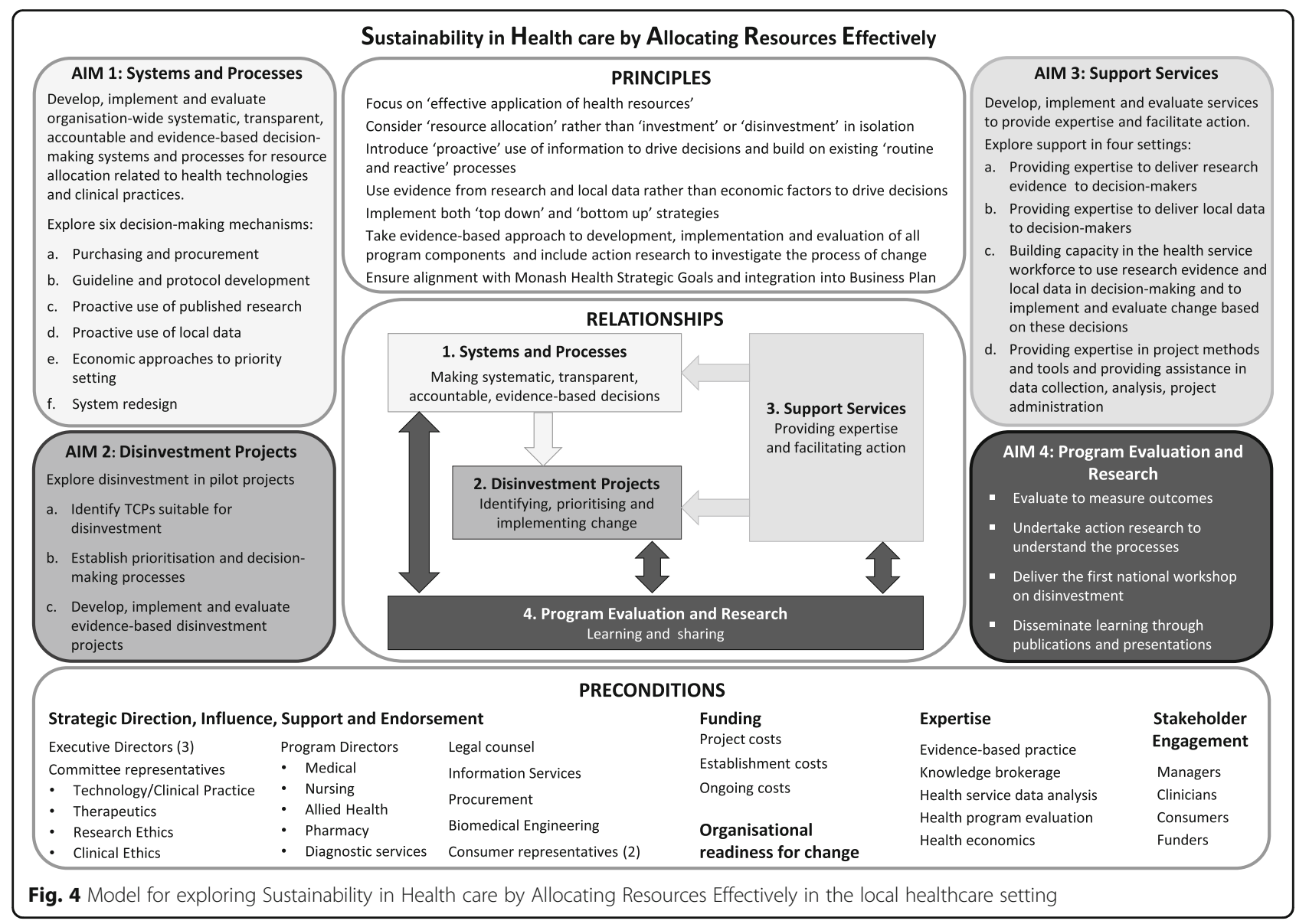

One aspect of the proposed model initially appeared to be a limitation, but when considered in light of the current literature may be seen as a strength. The available research in disinvestment was predominantly focused in health economics but Monash Health had no expertise in this area and did not intend to employ a health economist. The decision to take an 'evidencedriven' approach to disinvestment was based on the available in-house expertise. The proposed 'evidencedriven' model is novel and untested, however there are some encouraging findings in more recent research that indicate it might be well-suited to health service decision-making. Access to robust evidence, rather than an emphasis on cost saving, is thought to improve disinvestment decision-making and disinvestment is reported as more likely to be accepted by both clinicians and consumers if the focus is on quality and safety [40, 43]. Surveys indicate that most decision-makers in the health sector do not routinely use economic evaluations in their decisions $[14,44]$. Two large international surveys on use of evidence in decision-making have been conducted recently. Ninety-nine per cent of respondents from 15 countries indicated that systematic consideration of the available evidence would improve health system decision- making [45]. The second survey found that clinicians and policy-makers from 23 countries considered clinical effectiveness, safety, quality of evidence, disease severity and impact on healthcare costs to be the most relevant criteria [46]. A systematic review of decision criteria for resource allocation summarised the frequency of criteria cited by 40 studies: equity/fairness $(n=32)$, efficacy/effectiveness $(n=$ $29)$, stakeholder interests and pressures $(n=28)$, costeffectiveness $(n=23)$, strength of evidence $(n=20)$, safety $(n=19)$, mission and mandate of health system $(n=19)$, organizational requirements and capacity $(n=17)$, patientreported outcomes $(n=17)$ and need $(n=16)$ [47]. The proposed Monash Health 'evidence-driven' model and the suite of criteria used in the Technology/Clinical Practice Program [1] capture all these criteria so is likely to be compatible with current attitudes and behaviours of decision-makers.

\section{Limitations}

As there was no guidance on how to approach disinvestment from an organisation-wide perspective, the SHARE model was developed de novo by integrating theoretical and generic principles with staff and consumer experiences and perspectives. There is still a lack of information related to most of the strategies in the SHARE proposal and a 


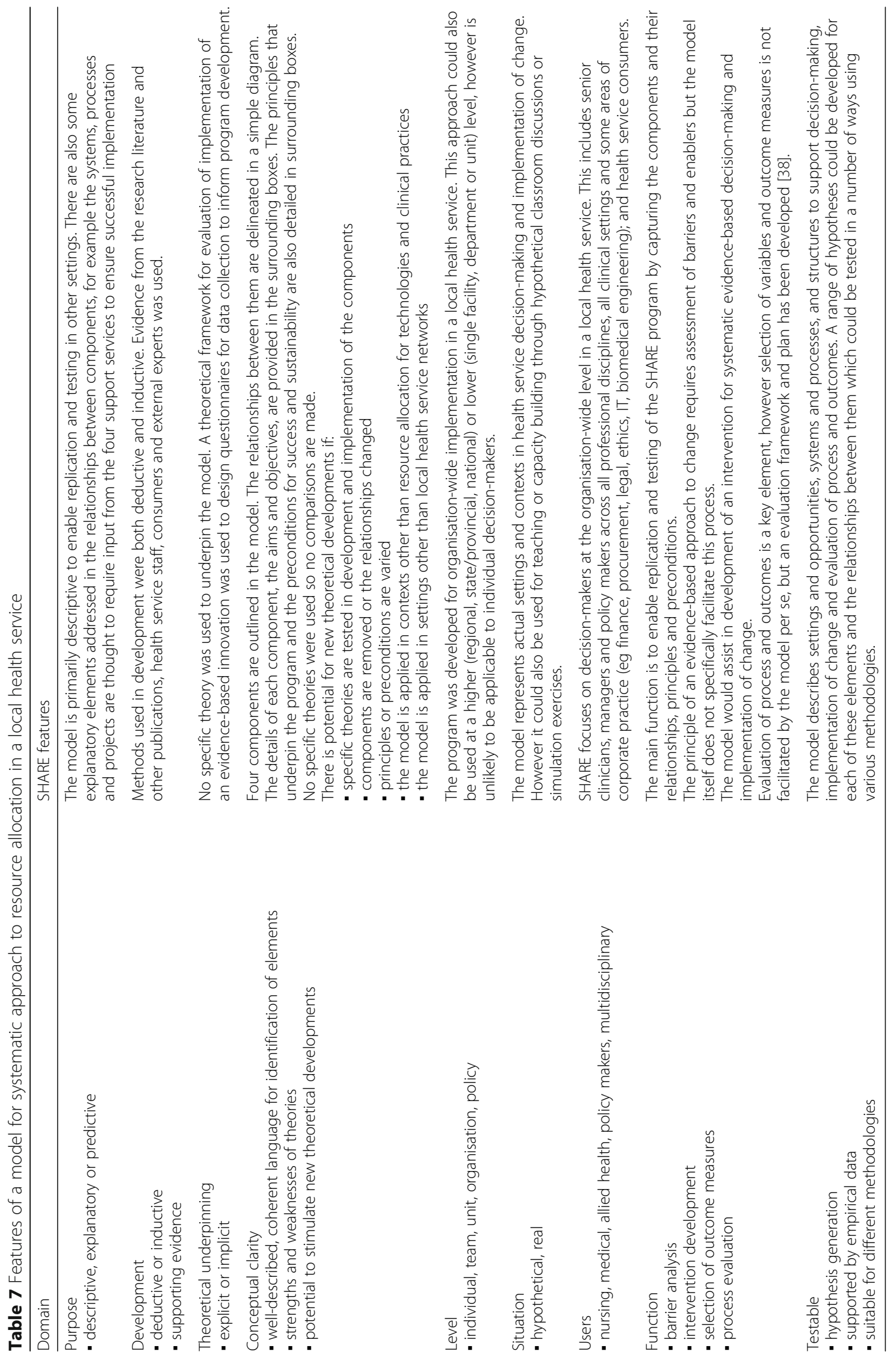


number of recent systematic reviews and discussion papers on disinvestment call for research in these areas $[4-7,11-15,40,48-56]$.

The only clear advice was to avoid the term 'disinvestment' due to the negative connotations and lack of common understanding. Although the name and general approach of SHARE was positive and steered away from the concept of 'disinvestment', a more appropriate term to describe the 'Disinvestment Projects' in Aim 2 proved elusive.

SHARE is about systems and processes in a health service, a complex dynamic organisation with a myriad of context-specific factors. The external validity of the proposed model and generalisability of the SHARE outcomes may be limited as a result. Health services in developed countries are very similar in many ways, but quite diverse in others. The diversity often lies in funding models and organisational culture, both of which may have a considerable impact on decision-making systems and processes for resource allocation. Health services in developing and resource-poor settings may be different in many additional ways that significantly reduce the applicability of findings from an Australian program. Other context-specific factors at local, regional or national level likely to affect generalisability are strategic direction, priorities, infrastructure, available project funding and leadership.

A wide group of stakeholders were engaged to represent consumers and all professional groups, at all relevant levels of seniority, across all campuses. Their responses were overwhelmingly similar with messages that were strong and consistent, which adds confidence to the validity of the process. However it should be kept in mind that those who agreed to participate are potentially more sympathetic to the ideas proposed and may not represent all views.

The project team responsible for delivering the SHARE Program at Monash Health were also the researchers investigating the processes undertaken. This has the potential to introduce subjectivity into the evaluations and limit insight if organisational assumptions are accepted without challenge. Extensive stakeholder involvement, transparency of methods and participation of an external evaluator in the role of 'critical friend' [38] were included in the SHARE processes to minimise these limitations.

The SHARE model utilises the in-house expertise of staff in evidence-based practice, knowledge brokerage and data analysis. Health services that do not have high-level skills in these areas may not be able to replicate this model without adaptation. The systematic approach could still be undertaken but with alternative drivers for change. Those with access to health economists in-house or in partnership with a local university could focus on economic principles, an option not available to Monash Health. Those without access to expertise in health economics or evidence-based decision-making may develop other methods such as a consensus-driven approach.

\section{Implications for policy and practice}

Local research identified a number of weaknesses in organisational decision-making such as lack of explicit criteria; limited use of evidence; staff under-skilled and underresourced to make, implement and evaluate evidencebased decisions; and minimal consumer involvement $[29,31]$. Monash Health is not unique and these issues are commonplace in health services around the world $[8,40,44,51,57-60]$. This indicates enormous opportunities for improvement through strategies that address these limitations.

The importance of allowing adequate time for development, implementation and evaluation of innovations is well established. Yet this is a constant tension in health services where a common response to an emerging problem is often urgent and reactive, delivered by staff with no experience in project management or change strategies, with inadequate resources and inappropriate timelines, which is not implemented or evaluated effectively $[29,40]$. It is anticipated that a systematic integrated approach to organisational decision-making for resource allocation will require considerable time, skills, resources and support, all of which are traditional challenges for health services, however once established the model will allow more timely reaction to future challenges.

\section{Implications for research}

SHARE is a suite of integrated initiatives to improve health service decision-making. Although the evaluation design is rigorous and an action research process is built around the program components to understand the process of change, the primary objective is quality improvement rather than research. As an exploratory study in the UK Medical Research Council framework for developing complex interventions [18], SHARE illustrates concepts, issues, barriers and enablers to evidence-based disinvestment in a local health service. These findings can be tested in controlled studies in a range of contexts to enable recommendations for effective practice.

The findings and decisions that underpinned program development are outlined (Table 4) and the model describes settings and opportunities, systems and processes, and structures to support decision-making, implementation of change, and evaluation of process and outcomes (Fig. 4). These details will enable replication of the program, testing of assumptions and comparison of characteristics of the environment, stakeholders and intervention.

There is potential for new theoretical developments if, for example:

- specific theories are tested in development and implementation of the components 
- components are removed or the relationships changed

- principles or preconditions are varied

- the model is applied in contexts other than resource allocation for TCPs

- the model is applied in settings other than local health service networks

\section{Conclusion}

A robust evidence-based investigation of the research literature and local knowledge with a range of stakeholders resulted in rich information with strong consistent messages. The process was made possible by provision of appropriate resources, expertise, time and support. The implications for disinvestment in the local healthcare setting were many and varied. The influencing factors were both positive and negative and addressed aspects of the internal and external environments, human factors, empirical decision-making, and practical applications. At the completion of Phase One, synthesis of the findings enabled development of frameworks and plans, and all preconditions for exploration of the four main aims in Phase Two were met. The model for sustainability in health care by allocating resources effectively can be replicated or adapted by health services wishing to establish a program for disinvestment and tested by researchers to confirm, refute or understand the processes involved.

\section{Additional file}

Additional file 1: Details of methods (PDF $366 \mathrm{~kb}$ )

\section{Abbreviations}

CCE: Centre for Clinical Effectiveness; DHS: Department of Human Services; iCARE: Compassion, Accountability, Respect, Excellence (Monash Health values); SHARE: Sustainability in Health care by Allocating Resources Effectively; TCPs: Technologies and clinical practices

\section{Acknowledgements}

The authors would like to acknowledge the contribution of others. Members of the SHARE Steering Committee for direction and guidance. CCE staff who undertook the early SHARE studies that contributed to development of the proposal for change and CCE staff members not on the SHARE team who provided help and support. Monash Health staff and consumer representatives who gave their time generously to share their thoughts and experiences. Delwyn Goodrick and Duncan Mortimer for expert assistance with health program evaluation and health economics.

\section{Funding}

The SHARE Program was funded by Monash Health and the Victorian Department of Human Services. No conditions related to the project or subsequent publications were imposed.

\section{Availability of data and materials}

Many of the datasets supporting the conclusions of the articles in the SHARE series are included within the articles and/or the accompanying additional files. Some datasets provide information for more than one article and are only provided once; where they are not included within an article and/or the accompanying additional file, the relevant citations to the articles in which they are provided are included. Datasets have not been made available where it is impossible to de-identify individuals due to the nature of survey or interview responses or where the data is published in confidential internal reports.

\begin{abstract}
Authors' contributions
$\mathrm{CH}, \mathrm{KA}$ and $\mathrm{CW}$ designed and implemented the methods and developed the proposal for change. $\mathrm{CH}$ developed the early frameworks, $\mathrm{CH}$ and SG conceived and developed the model. RK initiated the project. RK, WR, CK and MT provided guidance and direction for project decisions. $\mathrm{CH}$ drafted the initial manuscript. SG and CW provided critical revisions. KA, RK, WR, CK and MT provided later feedback. All authors read and approved the final manuscript.
\end{abstract}

\section{Authors' information}

$\mathrm{CH}$ was the Director of the Centre for Clinical Effectiveness and the SHARE Program Director. CH completed the SHARE publications as part of an unfunded PhD. KA was the SHARE Project Manager and CW was the Project Officer. SG is Professorial Fellow in the Monash University School of Public Health and Preventive Medicine and co-supervisor of $\mathrm{CH}^{\prime} \mathrm{s}$ PhD. RK was Director of Medicine Program, member of the SHARE Steering Committee and co-supervisor of CH's PhD. WR was Executive Director of Medical Services and Chair of SHARE Steering Committee. CK was Director of Medical Services. MT was Legal Counsel for Research and Ethics. RK, CK and MT were all members of the SHARE Steering Committee.

\section{Competing interests}

The authors declare that they have no competing interests.

\section{Consent for publication}

Not applicable

\section{Ethics approval and consent to participate}

The Monash Health Human Research and Ethics Committee (HREC) approved the SHARE program as a Quality Assurance activity. Further ethical review was not required as the program met the following criteria [61]:

- "The data being collected and analysed is coincidental to standard operating procedures with standard equipment and/or protocols;

- The data is being collected and analysed expressly for the purpose of maintaining standards or identifying areas for improvement in the environment from which the data was obtained;

- The data being collected and analysed is not linked to individuals; and

- None of the triggers for consideration of ethical review are present." [61] Participation was based on the 'opt-out approach' [61]. "The opt-out approach is a method used in the recruitment of participants into an activity where information is provided to the potential participant regarding the activity and their involvement and where their participation is presumed unless they take action to decline to participate."[61] Consent to participate was approved by the HREC based on the following criteria:

- Health care providers, managers, consumer representatives, and officers within government health departments will be informed about the project and the processes and invited to participate.

- Participation in interviews, workshops and/or surveys will be considered to be implied consent.

These conditions were met.

\section{Publisher's Note}

Springer Nature remains neutral with regard to jurisdictional claims in published maps and institutional affiliations.

\section{Author details}

${ }^{1}$ School of Public Health and Preventive Medicine, Monash University, Victoria, Australia. ${ }^{2}$ Centre for Clinical Effectiveness, Monash Health, Victoria, Australia. ${ }^{3}$ Medicine Program, Monash Health, Victoria, Australia. ${ }^{4}$ Medical Services and Quality, Monash Health, Victoria, Australia. ${ }^{5}$ Medical Services, Melbourne Health, Victoria, Australia. ${ }^{6}$ Ageing and Aged Care Branch, Department of Health and Human Services, Victoria, Australia.

Received: 11 March 2016 Accepted: 31 March 2017

Published online: 10 May 2017

References

1. Harris C, Garrubba M, Allen K, King R, Kelly C, Thiagarajan M, et al. Development, implementation and evaluation of an evidence-based 
program for introduction of new health technologies and clinical practices in a local healthcare setting. BMC Health Serv Res. 2015;15(1):575. doi:10. 1186/s12913-015-1178-4.

2. Harris C, Green S, Ramsey W, Allen K, King R. Sustainability in Health care by Allocating Resources Effectively (SHARE) 1: Introducing a series of papers reporting an investigation of disinvestment in a local healthcare setting. BMC Health Serv Res. 2017. doi:10.1186/s12913-017-2210-7.

3. Niven DJ, Mrklas KJ, Holodinsky JK, Straus SE, Hemmelgarn BR, Jeffs LP, et al. Towards understanding the de-adoption of low-value clinical practices: a scoping review. BMC Med. 2015;13:255. doi:10.1186/s12916-015-0488-z.

4. Healthcare Improvement Scotland. What approaches have been taken and efforts made to ensure public involvement in decision making relating to potential disinvestment in healthcare interventions and technologies? Technologies scoping report 16. 2013. Available from: http://www. healthcareimprovementscotland.org/our_work/technologies_and medicines/shtg_scoping_reports/technologies_scoping_report_16.aspx? Accessed: June 2015

5. Watt AM, Hiller JE, Braunack-Mayer AJ, Moss JR, Buchan H, Wale J, et al. The ASTUTE Health study protocol: deliberative stakeholder engagements to inform implementation approaches to healthcare disinvestment. Implement Sci. 2012;7:101. doi:10.1186/1748-5908-7-101.

6. Leggett L, MacKean G, Noseworthy T, Sutherland L, Clement F. Current status of health technology reassessment of non-drug technologies: survey and key informant interviews. Health Res Policy and Syst. 2012. doi:10.1186/ 1478-4505-10-38.

7. Schmidt DE. The development of a disinvestment framework to guide resource allocation decisions in health service delivery organizations. The University of British Columbia 2010. Available from: https://open.library.ubc. ca/clRcle/collections/ubctheses/24/items/1.0073252. Accessed 17 Apr 2017.

8. Rooshenas L, Owen-Smith A, Hollingworth W, Badrinath P, Beynon C, Donovan JL. "I won't call it rationing...": an ethnographic study of healthcare disinvestment in theory and practice. Soc Sci Med. 2015;128:27381. doi:10.1016/j.socscimed.2015.01.020.

9. Harris C, Allen K, King R, Ramsey W, Kelly C, Thiagarajan M. Sustainability in Health care by Allocating Resources Effectively (SHARE) 2: Identifying opportunities for disinvestment in a local healthcare setting. BMC Health Serv Res. 2017. doi:10.1186/s12913-017-2211-6.

10. Flodgren G, Rojas-Reyes MX, Cole N, Foxcroft DR. Effectiveness of organisational infrastructures to promote evidence-based nursing practice. Cochrane database of systematic reviews (Online). 2012;2:CD002212. doi:10. 1002/14651858.CD002212.pub2

11. Daniels T, Williams I, Robinson S, Spence K. Tackling disinvestment in health care services. The views of resource allocators in the English NHS. J Health Organ Manag. 2013;27(6):762-80.

12. Robinson S, Williams I, Dickinson H, Freeman T, Rumbold B. Priority-setting and rationing in healthcare: evidence from the English experience. Soc Sci Med. 2012;75(12):2386-93. doi:10.1016/j.socscimed.2012.09.014.

13. Smith N, Mitton C, Peacock S, Cornelissen E, MacLeod S. Identifying research priorities for health care priority setting: a collaborative effort between managers and researchers. BMC Health Serv Res. 2009;9:165. doi:10.1186/1472-6963-9-165

14. Eddama O, Coast J. A systematic review of the use of economic evaluation in local decision-making. Health Policy. 2008;86(2-3):129-41. doi:10.1016/j. healthpol.2007.11.010.

15. Hamilton S, Huby G, Tierney A, Powell A, Kielmann T, Sheikh A, et al. Mind the gap between policy imperatives and service provision: a qualitative study of the process of respiratory service development in England and Wales. BMC Health Serv Res. 2008;8:248. doi:10.1186/1472-6963-8-248.

16. Riley BL, Robinson KL, Gamble J, Finegood DT, Sheppard D, Penney TL, et al. Knowledge to action for solving complex problems: insights from a review of nine international cases. Health promotion chronic dis prev Canada. 2015;35(3):47-53.

17. Harris C, Turner T, Wilkinson F. SEAchange: Guide to a pragmatic evidencebased approach to Sustainable, Effective and Appropriate change in health services. 2015. Available from: http://arrow.monash.edu.au/hdl/1959.1/ 1225377. Accessed 17 Apr 2017.

18. Campbell NC, Murry E, Darbyshire J, Emery J, Farmer A, Griffiths F, et al. Designing and evaluating complex interventions to improve health care. BMJ. 2007;334:455-9.

19. Meyer J. Qualitative research in health care. Using qualitative methods in health related action research. BMJ. 2000;320(7228):178-81.
20. Meyer J. Evaluating action research. Age Ageing. 2000;29 Suppl 2:8-10.

21. NVivo qualitative data analysis software Version 8. QSR International Pty Ltd; 2008.

22. Hsieh HF, Shannon SE. Three approaches to qualitative content analysis. Qual Health Res. 2005;15(9):1277-88. doi:10.1177/1049732305276687.

23. Srivastava A, Thomson SB. Framework analysis: a qualitative methodology for applied policy research. JOAAG. 2009:4(4):72-9.

24. Grol R, Grimshaw J. From best evidence to best practice: effective implementation of change in patients' care. Lancet. 2003;362(9391):1225-30.

25. Grol R, Wensing M, Eccles M. Improving practice: A systematic approach to implementation of change in patient care. Oxford: Elsevier Science; 2004.

26. Greenhalgh T, Robert G, Macfarlane F, Bate P, Kyriakidou O. Diffusion of innovations in service organizations: systematic review and recommendations. Milbank Q. 2004;82(4):581-629. doi:10.1111/j. 0887-378X.2004.00325.X.

27. Health NSW. A Framework for Building Capacity to Improve Health. Sydney: Better Health Centre, NSW Health Department; 2001.

28. Rycroft-Malone J, Bucknall TK, editors. Models and Frameworks for Implementing Evidence-Based Practice: Linking Evidence to Action. Evidence-Based Nursing. Chichester: Wiley-Blackwell; 2010.

29. Harris C, Allen K, Waller C, Brooke V. Sustainability in Health care by Allocating Resources Effectively (SHARE) 3: Examining how resource allocation decisions are made, implemented and evaluated in a local healthcare setting. BMC Health Serv Res. 2017. doi:10.1186/s12913-017-2207-2.

30. Harris C, Ko H, Waller C, Sloss P, Williams P. Sustainability in Health care by Allocating Resources Effectively (SHARE) 4: Exploring opportunities and methods for consumer engagement in resource allocation in a local healthcare setting. BMC Health Serv Res. 2017. doi:10.1186/s12913-017-2212-5.

31. Harris C, Allen K, Waller C, Dyer T, Brooke V, Garrubba M et al. Sustainability in Health care by Allocating Resources Effectively (SHARE) 7: Supporting staff in evidence-based decision-making, implementation and evaluation in a local healthcare setting. BMC Health Serv Res. 2017. in press.

32. Harris C, Garrubba M, Melder A, Voutier C, Waller C, King R et al. Sustainability in Health care by Allocating Resources Effectively (SHARE) 8: Developing, implementing and evaluating an Evidence Dissemination Service in a local healthcare setting. BMC Health Serv Res. 2017. in press.

33. Rumbold G, Allen K, Harris C. Disinvestment of technologies and clinical practices in health services: Conceptual and policy perspectives. Centre for Clinical Effectiveness, Southern Health 2008. Available from: http://arrow. monash.edu.au/hdl/1959.1/1218935. Accessed 17 Apr 2017.

34. Harris C, Allen K, Waller C, Voutier C, Brooke V. Health technology disinvestment: tests, drugs and clinical practice. Report on a national disinvestment workshop. Part 1: Report. Centre for Clinical Effectiveness 2009. Available from: http://arrow.monash.edu.au/hdl/1959.1/1218926. Accessed: October 2016

35. Harris C, Allen K, Waller C, Voutier C, Brooke V. Health technology disinvestment: tests, drugs and clinical practice. Report on a national disinvestment workshop. Part 2: Appendices. Centre for Clinical Effectiveness 2009. Available from: http://arrow.monash.edu.au/hdl/1959.1/ 1218922. Accessed 17 Apr 2017.

36. Harris C, Allen K, Brooke V, Dyer T, Waller C, King R et al. Sustainability in Health care by Allocating Resources Effectively (SHARE) 6: Investigating methods to identify, prioritise, implement and evaluate disinvestment projects in a local healthcare setting. BMC Health Serv Res 2017. in press.

37. Harris C, Allen $K$, Waller C, Dyer $T$, King R, Ramsey W. Sustainability in Health care by Allocating Resources Effectively (SHARE) 11: Reporting outcomes of an evidence-driven approach to disinvestment in a local healthcare setting. BMC Health Serv Res. 2017. in press.

38. Centre for Clinical Effectiveness. Sustainability in Healthcare by Allocating Resources Effectively (SHARE): Evaluation and Research Plan. Southern Health 2009. Available from: https://figshare.com/articles/Sustainability_in_ Healthcare_by_Allocating_Resources_Effectively_SHARE_Evaluation_and_ Research_Plan/3979575. Accessed 17 Apr 2017.

39. Ilott I, Gerrish K, Laker S, Bray K. Naming and framing the problem: using theories, models and conceptual frameworks. Bridging the gap between knowledge and practice. Your starter for 10: No.2. Sheffield Teaching Hospital NHS Foundation Trust, National Institute for Health Research Collaboration for Leadership in Applied Health Research and Care for South Yorkshire 2013

40. Hollingworth W, Rooshenas L, Busby J, Hine CE, Badrinath P, Whiting $P F$, et al. Using clinical practice variations as a method for 
commissioners and clinicians to identify and prioritise opportunities for disinvestment in health care: a cross-sectional study, systematic reviews and qualitative study. Southampton: Queen's Printer and Controller of HMSO 2015; 2015.

41. Harris C, Green S, Ramsey W, Allen K, King R. Sustainability in Health care by Allocating Resources Effectively (SHARE) 9: Conceptualising disinvestment in the local healthcare setting BMC Health Serv Res. 2017. in press.

42. Harris C, Green S, Elshaug AG. Sustainability in Health care by Allocating Resources Effectively (SHARE) 10: Operationalising disinvestment in an evidence-based framework for resource allocation. BMC Health Serv Res. 2017. in press.

43. HealthPACT. Disinvestment in Australia and New Zealand. Health Policy Advisory Committee on Technology 2013. Available from: http://www. health.qld.gov.au/healthpact/docs/papers/workshop/disinvestment-report. pdf. Accessed 17 Apr 2017.

44. Eddama O, Coast J. Use of economic evaluation in local health care decision-making in England: a qualitative investigation. Health policy. 2009; 89(3):261-70. doi:10.1016/j.healthpol.2008.06.004.

45. Vogel JP, Oxman AD, Glenton C, Rosenbaum S, Lewin S, Gulmezoglu AM, et al. Policymakers' and other stakeholders' perceptions of key considerations for health system decisions and the presentation of evidence to inform those considerations: an international survey. Health res policy and syst/BioMed Central. 2013;11:19. doi:10.1186/1478-4505-11-19.

46. Tanios N, Wagner M, Tony M, Baltussen R, van Til J, Rindress D, et al. Which criteria are considered in healthcare decisions? Insights from an international survey of policy and clinical decision makers. Int J Technol Assess Health Care. 2013;29(04):456-65. doi:10.1017/S0266462313000573.

47. Guindo LA, Wagner M, Baltussen R, Rindress D, van Til J, Kind P, et al. From efficacy to equity: Literature review of decision criteria for resource allocation and healthcare decisionmaking. Cost effectiveness and resource allocation : C/E. 2012;10(1):9. doi:10.1186/1478-7547-10-9.

48. Cooper C, Starkey K. Disinvestment in health care. BMJ. 2010;340. doi:10. 1136/bmj.c1413

49. Henshall C, Schuller T, Mardhani-Bayne L. Using health technology assessment to support optimal use of technologies in current practice: the challenge of "disinvestment". Int J Technol Assess Health Care. 2012;28(3): 203-10. doi:10.1017/s0266462312000372.

50. Garner S, Littlejohns P. Disinvestment from low value clinical interventions: NICEly done? BMJ. 2011;343(jul27 2):d4519-d. doi:10.1136/bmj.d4519.

51. Evans BA, Snooks H, Howson H, Davies M. How hard can it be to include research evidence and evaluation in local health policy implementation? Results from a mixed methods study Implementation science. 2013;8:17. doi:10.1186/1748-5908-8-17.

52. Gerdvilaite J, Nachtnebel A. Disinvestment: overview of disinvestment experiences and challenges in selected countries. HTA- Projektbericht., vol Nr. 57. Ludwig Boltzmann Institut für Health Technology Assessment; 2011

53. Leggett L, Noseworthy TW, Zarrabi M, Lorenzetti D, Sutherland LR, Clement FM. Health technology reassessment of non-drug technologies: current practices. Int J Technol Assess Health Care. 2012;28(3):220-7. doi:10.1017/ S0266462312000438.

54. Garcia-Armesto S, Campillo-Artero C, Bernal-Delgado E. Disinvestment in the age of cost-cutting sound and fury. Tools for the Spanish National Health System. Health policy. 2013;110(2-3):180-5. doi:10.1016/j. healthpol.2013.01.007.

55. Polisena J, Clifford T, Elshaug AG, Mitton C, Russell E, Skidmore B. Case studies that illustrate disinvestment and resource allocation decision-making processes in health care: A systematic review. Int J Technol Assess Health Care. 2013;29(2):174-84. doi:10.1017/ s0266462313000068.

56. Abelson J, Bombard Y, Gauvin FP, Simeonov D, Boesveld S. Assessing the impacts of citizen deliberations on the health technology process. Int J Technol Assess Health Care. 2013:29(03):282-9. doi:10.1017/ S0266462313000299

57. Fronsdal KB, Facey K, Klemp M, Norderhaug IN, Morland B, Rottingen JA. Health technology assessment to optimize health technology utilization: using implementation initiatives and monitoring processes. Int J Technol Assess Health Care. 2010;26(3):309-16. doi:10.1017/ s0266462310000309.

58. Mitton C, Donaldson C. Setting priorities in Canadian regional health authorities: a survey of key decision makers. Health policy. 2002;60(1):39-58. http://dx.doi.org/10.1016/S0168-8510(01)00190-7.
59. Chitama D, Baltussen R, Ketting E, Kamazima S, Nswilla A, Mujinja PG. From papers to practices: district level priority setting processes and criteria for family planning, maternal, newborn and child health interventions in Tanzania. BMC Womens Health. 2011:11:46. doi:10.1186/1472-6874-11-46.

60. Innvaer S, Vist G, Trommald M, Oxman A. Health policy-makers' perceptions of their use of evidence: a systematic review. J Health Serv Res Policy. 2002; 7(4):239-44. doi:10.1258/135581902320432778.

61. National Health and Medical Research Council. Ethical Considerations in Quality Assurance and Evaluation Activities. Canberra: Commonwealth of Australia; 2014.

\section{Submit your next manuscript to BioMed Central and we will help you at every step:}

- We accept pre-submission inquiries

- Our selector tool helps you to find the most relevant journal

- We provide round the clock customer support

- Convenient online submission

- Thorough peer review

- Inclusion in PubMed and all major indexing services

- Maximum visibility for your research

Submit your manuscript at www.biomedcentral.com/submit
Biomed Central 